\title{
Thousands Shades of Microbes: Micro-Paint by Nature
}

\author{
Girish B Mahajan ${ }^{1 *}$ and Dipali Rahul Phatak ${ }^{2}$ \\ ${ }^{1}$ HiMedia laboratories Pvt. Ltd., Mumbai, India \\ ${ }^{2} J o g e s h w a r i$ Education Society, Mumbai, India \\ *Corresponding Author: Girish B Mahajan, HiMedia laboratories Pvt. Ltd., \\ Mumbai, India.
}

Received: April 03, 2020

Published: May 20, 2020

(C) All rights are reserved by Girish B

Mahajan and Dipali Rahul Phatak.

\begin{abstract}
Many microbes are ubiquitous in producing and secreting out colors. There are several live examples of vibrant microbial coloured ecological units in nature. Man has always explored potential applications for the excellent quality of colour produced by microbes. The metabolic economics in microbes is very conservative and therefore microbes produce something only if it has a role in its own existence, protection and maintenance. For microbes, pigments are secondary metabolites; however, for humankind it is a great opportunity to explore the ability of microbes to produce safe natural pigments for use in day to day life. The need for safe and naturally occurring (edible) colouring agents has tremendously increased on the background of carcinogenic and teratogenic nature of many synthetic colouring agents. It will be interesting to know some unique features of these and potential applications of such microbes and their pigments.
\end{abstract}

Keywords: Microbes; Micro-paint; Nature

\section{An introduction to colour shades of microbes}

Colour is one of the most comprehensive inputs perceived by the human eyes. Colour is a significant communication tool and is used for signalling, influence mood, go into comfort mood, cheer the mind and heart and even influence physiological reactions. The world of glamour, social media, costumes, food and beverages, entertainment, decoration, corporate branding, product marketing, packaging formats, floral configurations in gardens etc. are dependent on colours for an effective display and output. Humans, the most evolved creature on the earth, cannot imagine day to day life without colour. Even the most primitive creature; microbes, are naturally colourful and without which the micro-world would be so drab.

These micro-painters use genomic brushes to secrete pigments in nature. It is believed that humans devised pigments using a combination of soil, animal fat and burned charcoal as early as 40,000 years ago. Microbes have been colouring nature for more than a million years. Natural colours are obtained from colour imparting compounds in living systems known as pigments. Diversity of pigments depends on differences in their chemical structure and presence of specific chromophores. Chromophores are molecular groups, which impart specific colour to pigments. Some of which are water-soluble while others are soluble in organic solvents such as chloroform, and alcohol. Thousands of shades of colours are due to a slight chemical changes in the chromophore.

\section{Magic of microbial colour in nature}

There are several live examples of vibrant microbial coloured ecological units in nature. In the very pink Lake Hillier ${ }^{1}$ (Figure 1) located on Middle Island off the coast of Western Australia, the pink colour is caused due to salt-loving Halobacteria and an algae known as Dunaliella salina, which thrive in salty environments. A large bloom of cyanobacteria commonly known as blue-green algae, spread across Guatemala's Lake Atitlán ${ }^{2}$ (Figure 2) in green filaments and strands. The dark red coloured Lake Natron in the Arusha Region of Tanzania, Africa is due to heavy growth of red cyanobacteria (Pigment: phycoerythrin). The living bacterial colours of the Yellowstone region stunned early explorers. Geologist Ferdinand Hayden turned into a poet when he exclaimed in 1871 about the beautiful colour patches by microbes.

${ }^{1}$ https://science.howstuffworks.com/life/cellular-microscopic/australia-pink-lakes.htm

${ }^{2}$ https://earthobservatory.nasa.gov/images/41385/harmful-bloom-in-lake-atitlan-guatemala 


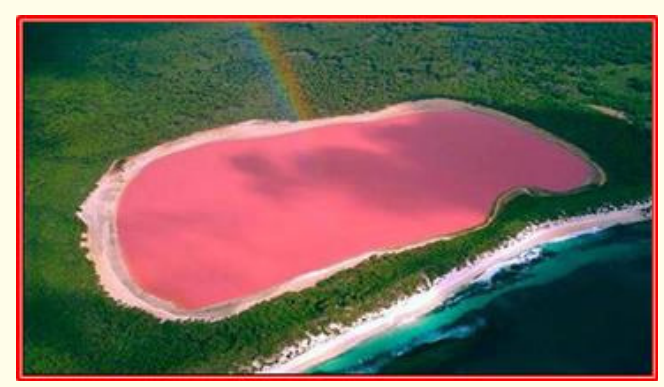

Figure 1: Pink Lake.

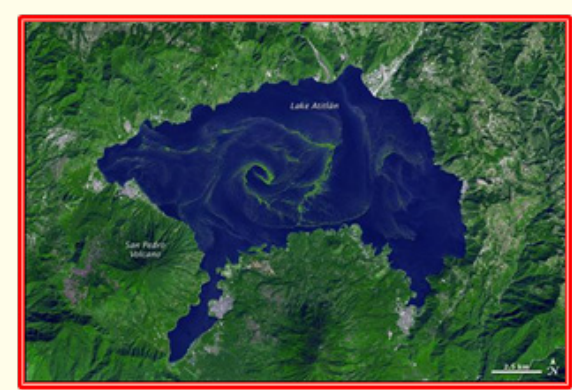

Figure 2: Blue bloom of cyanobacteria.

\section{Types, range and chemical nature of colours}

Man has always explored potential applications for the excellent quality of colour produced by microbes. Some of the most significant natural pigments are carotenoids, flavonoids, tetrapyrroles and xanthophyll (e.g. Astaxanthin). Some important colours and sources are mentioned in the table below.

Why do microbes produce pigments?

The metabolic economics in microbes is very conservative and therefore microbes produce something only if it has a role in its own existence, protection and maintenance. Pigments have defi-

\begin{tabular}{|lll|}
\hline \multicolumn{1}{c}{ Color } & Chemical name & \multicolumn{1}{c|}{ Producing microbe } \\
\hline Yellow & Ankaflavin & Monascus sp. \\
\hline Yellow-orange & Beta Carotene & Mucor circinelloides \\
\hline Orange & Torularhodin & Rhodotorula sp. \\
\hline Red & Lycopene & Fusarium sporotrichioides \\
Pink-red & Astaxanthin & Paracoccus carotinifaciens \\
Green-yellow & Scytonemin & Cyanobacteria \\
Blue & Actinorhodin & Streptomyces coelicolor \\
Purple & Violacein & Chromobacterium violaceum \\
\hline
\end{tabular}

Table nite roles in the life of microbes. Some pigments provide protection to microbes from UV rays, such as the golden yellow pigment produced by Staphylococcus aureus. Many of the yellow to orange pigments act as antioxidants relieving oxygen stress. The carotenoid pigments isolated from Micrococcus roseus and Micrococcus luteus showed promising UV-protective and antibacterial properties. In a study done at the Department of Radiation Biology, German Aerospace Centre in Germany, a red carotene-like pigment of the spores of Bacillus atrophaeus-DSM 675 was reported to affect the resistance of spores to environmental UV-A radiation. Bacterialphotosynthesis is a major reason for bacterial pigment production (chlorophylls, carotenoids), e.g. green and purple sulphur bacteria. Pyocyanin produced by Pseudomonas aeruginosa is a virulence weapon as it is toxic to bacterial and higher cells due to the reactive oxygen intermediates it generates. These pigments demonstrate why the thousands of shades secreted by microbes in their tiny world have a high impact.

How human explores the colourful potential of tiny natural painters?

For microbes, pigments are secondary metabolites; however, for humankind it is a great opportunity to explore the ability of microbes to produce safe natural pigments for use in day to day life. Scientists have isolated food-grade pigments from bacteria and blue pigment from cultured soil bacteria that offer a natural colour with excellent stability. Bacterial colorants such as Canthaxanthin are already being used in the fish industry to enhance the pink colour of farmed salmon. Anthocyanins have a wide range of biological applications such as decreasing the risk of cancer, reducing inflammatory reactions, and modulating immune response. A red pigment, prodigiosin produced by the genus Serratia, is an antibiotic, has an antimalarial effect and shows immunosuppressing property. Recently it was reported that prodigiosin could be used to colour five types of fabric viz. acrylic, polyester microfiber, polyester, silk and cotton. Similar textile-dyeing ability was also reported for Janthinobacterium lividum. Violacein is reported to have antiviral, antiprotozoal, anticancer, antibacterial, and antioxidant properties. Astaxanthin is an approved colouring agent used in fish and animal foods. Phycocyanin pigment from blue green bacteria is used in the cosmetics industry. Natsai Audrey Chieza is the founder of the UK based bio-design research studio Faber Futures London. Chieza works with blue pigment of Streptomyces coelicolor, as colorant for designer costumes. Recently a group of Korean researchers, working on fighting against superbugs, have developed antibacterial masks using Violacein. 
What is next for microbe-derived pigments?

The market share of microbes and microbial products seems to be significant and holds large commercial potential in the future. The need for safe and naturally occurring (edible) colouring agents has tremendously increased in response to carcinogenic and teratogenic nature of synthetic colouring agents. Presently, the cost of natural colours is higher compared to synthetic colours. However, this challenge can be overcome by mass biotechnical production of natural colours, and greater use of genetic methods to improve the yield and reduce costs. To achieve cost reduction, rigorous efforts are required to develop a cheap organic substrate for growing colour producing microorganisms. Future investigations also need to be focused on the chemical structure-function relationship of microbial pigments. With competitive costs, soon our walls may be adorned by shades developed by these tiny painters.

\section{Assets from publication with us}

- Prompt Acknowledgement after receiving the article

- Thorough Double blinded peer review

- Rapid Publication

- Issue of Publication Certificate

- High visibility of your Published work

Website: https://www.actascientific.com/

Submit Article: https://www.actascientific.com/submission.php

Email us: editor@actascientific.com

Contact us: +919182824667 